\title{
Mengenalkan Warna Melalui Model Pembelajaran Picture and Picture pada Anak Usia Dini
}

\author{
${ }^{1}$ Kamtini, ${ }^{2}$ Salsabila Hasiana Tanjung, ${ }^{3}$ Eva Eriani \\ ${ }^{1}$ Universitas Negeri Medan, Sumatera Utara, Indonesia \\ ${ }^{2}$ Universitas Negeri Medan, Sumatera Utara, Indonesia \\ ${ }^{3}$ STAI Auliaurrasyidin, Tembilahan, Riau, Indonesia
}

\section{INFORMASI \\ ARTIKEL}

Artikel Histori:

Diterima :

$30 / 11 / 2020$

Direvisi :

15/06/2021

Diterbitkan:

31/07/2021

\section{Keywords: \\ Introducing colors, \\ Picture and \\ picture, \\ Early childhood}

Kata Kunci:

Mengenalkan

warna,

Picture and

picture,

Anak usia dini

\section{DOI:}

https://doi.org/

10.46963/mash.v

4i02.233

\author{
Korespondensi \\ Penulis: \\ Salsabila Hasiana \\ Tanjung \\ hasianasalsabila@ \\ gmail.com
}

\begin{abstract}
Cognitive abilities include various things, one of which is the ability to recognize colors. However, the ability to recognize colors is less often ruled out by educators and parents. This can be seen from learning that pays more attention to early reading and arithmetic skills. In fact, the ability to recognize colours is a very important aspect for children's brain development. This research was conducted in order to see the role of picture and picture learning in stimulating children to recognize colours. This research is a quantitative research using a quasi-experimental method with one group time-series test. The data obtained were analysed using a regression test to see the effect of the treatment given. The results showed a significance value of 0.00 which was smaller than 0.05 , which means the picture and picture learning model has a significant effect on the ability to recognize colours in early childhood.
\end{abstract}

ABSTRAK: Kemampuan kognitif meliputi berbagai hal, salah satunya kemampuan mengenal warna. Namun, kemampuan mengenal warna sering diabaikan oleh para pendidik dan orang tua. Hal ini terlihat dari pembelajaran yang lebih memperhatikan kemampuan membaca maupun berhitung awal. Padahal kemampuan mengenal warna ini merupakan aspek yang sangat penting bagi perkembangan otak anak. Penelitian ini dilakukan agar dapat melihat peranan pembelajaran picture and picture dalam menstimulasi anak dalam mengenal warna. Penelitian ini berupa penelitian kuantitatif menggunakan metode quasi eksperiment dengan uji one group-time series. Data yang diperoleh dianalisis menggunakan uji regresi untuk melihat keberpengaruhan treatment yang diberikan. Hasil penelitian menunjukkan nilai signifikasi 0.00 yang lebih kecil dari 0.05 , yang berarti model pembelajaran picture and picture berpengaruh secara signifikan terhadap kemampuan mengenal warna pada anak usia dini.

\section{Cara mensitasi artikel:}

Kamtini, Tanjung, S. H., \& Eriani, E. (2021). Mengenalkan Warna Melalui Model Pembelajaran Picture and Picture Pada Anak Usia Dini. Mitra Ash-Shibyan: Jurnal Pendidikan dan Konseling, 4(02), 81-90. https://doi.org/10.46963/mash.v4i02.233 


\section{PENDAHULUAN}

Proses kognisi meliputi berbagai aspek seperti persepsi, ingatan, pikiran, simbol, penalaran, dan pemecahan masalah. Perkembangan kognitif merupakan aspek yang sangat penting untuk dikembangkan karena melalui perkembangan kognitif anak dapat memperoleh kemampuan dalam berpikir, memecahkan masalah dan mengembangkan kemampuan logika yang berpengaruh pada perkembangan anak selanjutnya.

Pemrosesan informasi ketika anak mengenal konsep warna dimulai dari proses penyandingan informasi (encoding) diikuti dengan penyimpanan informasi (storage) dan diakhiri dengan mengungkapkan kembali informasi-informasi yang telah disimpan dalam ingatan (retrieval). Ingatan terdiri dari struktur informasi yang terorganisasi dan proses penelusurannya bergerak secara hierarkis, dari informasi yang paling umum dan rinci sampai informasi yang diinginkan diperoleh.

Mengenal warna bagi anak awalnya adalah bagaimana otak menginterpretasikannya. Ketika anak usia dini melihat warna, dari benda yang jauh maupun dekat memerlukan fokus dan konsentrasi terhadap objek yang dilihat. Meningkatkan ketajaman melihat warna atau benda anak usia dini dan Taman Kanak-kanak perlu memperhatikan tiga hal, yaitu discriminate (perbedaan perhatian diantara obyek yang dilihat), integrite (kondisi antara makna penglihatan), dan memory (gerak dan memori) (Macdonald, et al: 2020).

Kemampuan mengenal warna merupakan salah satu aspek dari kemampuan kognitif. Kemampuan mengenal warna pada anak usia dini merupakan hal yang sangat penting bagi perkembangan otaknya, sebab pengenalan warna pada anak usia dini dapat merangsang indera penglihatan otak (Lopatovska, et al: 2020). Warna juga dapat memancing kepekaan terhadap penglihatan yang terjadi karena warna yang ada pada benda terkena sinar matahari baik secara langsung atau tidak langsung yang kemudian dapat dilihat oleh mata (Macdonald, et al: 2020).

Mengenal warna berasal dari dua kata, mengenal dan warna. Mengenal artinya mengetahui, sedangkan warna berarti kesan yang diperoleh mata dari cahaya yang dipantulkan oleh benda-benda yang dikenalnya (Sukinten: 2014). Mengenal warna berarti kecakapan untuk mengetahui cahaya yang dipantulkan oleh benda yang dikenalnya (warna). Pada penelitian ini yang dimaksud mengenal warna adalah 
kecakapan anak untuk memenuhi standar tingkat pencapaian perkembangan (STPPA) yang termuat dalam Permendikbud 137 Tahun 2014

Ruang lingkup yang harus dikuasai dalam kemampuan kognitif anak khususnya anak TK usia 4-5 tahun salah satunya adalah mengenal konsep warna (Febriana: 2012; Raj \& Ganapathy: 2019). Tingkat pencapaian perkembangan pengenalan warna anak usia 4-5 tahun menurut STPPA antara lain mengklasifikasikan benda berdasarkan warna, mengklasifikasikan benda kedalam kelompok (warna) yang sama, (warna) sejenis atau kelompok yang berpasangan dengan 2 variasi; mengenal pola (warna) $\mathrm{AB}-\mathrm{AB}$ dan $\mathrm{ABC}-\mathrm{ABC}$; dan mengurutkan benda berdasarkan 5 seriasi warna. Capaian perkembangan anak tersebut dapat disimpulkan bahwa kemampuan kognitif mengenal warna anak usia 4-5 tahun harus dapat mencakup kelima hal tersebut, yang bertujuan agar anak mampu mengetahui pengetahuan umum dan sains, konsep warna, ukuran, bentuk dan pola, konsep bilangan, lambang bilangan dan huruf (Erviana, et al: 2019).

Melatih anak usia dini dalam mengenalkan warna dengan cara menunjukkan pola stimulasi untuk mengenal, mengklasifikasikan, dan mengorganisir suatu obyek yang berwana yang dilihat secara runtut untuk menghasilkan kesan perasaan warna, sehingga anak dapat memiliki kemampuan mengenal warna baik kemampuan menunjuk, menyebut, dan mengelompokkan warna. Berdasarkan hal tersebut kemampuan mengenal warna dalam perkembangan kognitif anak merupakan salah satu proses penerimaan informasi yang sebelumnya diberikan stimulasi dari proses encoding, storage, kemudian retrieval melalui kegiatan-kegiatan yang digunakan guru sehingga melalui proses tersebut anak dapat menunjuk, menyebut, dan mengelompokkan warna (Marchak, et al: 2020). Namun pada kenyataannya, model pembelajaran yang diterapkan untuk mengenalkan warna masih kurang variatif. Warna lebih sering dikenalkan pada saat kegiatan menggambar saja, dan menyebutkan warna benda-benda di lingkungan sekitar. Padahal anak sangat tertarik dengan segala sesuatu yang berwarna-warni karena itu sebagai guru seharusnya dapat memaksimalkan dengan memberikan model pembelajaran yang lebih variatif.

Guru sangat berperan dalam memberikan stimulus untuk mengembangkan kemampuan kognitif terutama pada kemampuan 
mengenal warna. Kemampuan mengenal warna sering abaikan oleh para pendidik bahkan orang tua. Hal ini terlihat dari pembelajaran yang lebih memperhatikan kemampuan membaca dan berhitung awal. Padahal kemampuan mengenal warna ini merupakan aspek yang sangat penting bagi perkembangan otak anak. Karena kemampuan mengenal warna sejak dini dapat merangsang indera penglihatan dan merangsang kemampuan anak mengenal serta mengekspresikan warna yang ada di lingkungan seperti menyebutkan warna bunga, daun, pakaian, dan lain sebagainya secara tepat.

Standar Tingkat Pencapaian Perkembangan Anak (STPPA) menjelaskan bahwa seharusnya anak usia 4-5 tahun sudah mampu mengenal 11 warna. Akan tetapi, berdasarkan hasil observasi menunjukkan bahwa kemampuan mengenal warna belum berkembang secara optimal yang terlihat dari sebagian besar anak kesulitan dalam mengenal warna. Pada saat pembelajaran di kelas anak menunjukkan keragu-raguan dan kesulitan melaksanakan instruksi guru untuk menunjuk, menyebut, dan mengelompokkan warna. Selain itu, kemampuan anak dalam menunjukkan suatu warna seperti warna kuning belum kompak, ada yang menunjukkan warna kuning ada pula yang menunjukkan warna jingga. Begitu pula dalam membedakan warna biru dan hijau, anak-anak masih kesulitan menunjukkannya. Dengan kata lain, kemampuan anak mengenal warna belum berkembang dengan optimal.

Berbagai permasalahan ini juga disebabkan beberapa faktor lain seperti kurangnya motivasi belajar anak, pemikiran orang tua dan guru yang mengesampingkan pengetahuan tentang mengenal warna dan lebih mementingkan pengetahuan angka serta huruf (Hidayati, Robingatin, Saugi: 2020). Strategi pengenalan warna hanya menggunakan kertas origami, ketika kegiatan menggambar, serta melalui metode bercakapcakap.

Mengenalkan warna membutuhkan pembelajaran yang menyenangkan bagi anak. Selain menyenangkan, pembelajaran yang diberikan diharapkan dapat bermakna bagi capaian perkembangan anak. Model pembelajaran picture and picture menjadi salah satu pilihan dalam pembelajaran mengenalkan warna bagi anak usia dini (Pradina \& Hastuti: 2017). Model pembelajaran Picture and Picture merupakan suatu pembelajaran yang menggunakan peran gambar yang dipasangkan atau diurutkan menjadi urutan logis berdasarkan tujuan pembelajaran (Harvey

84 mitra Ash-Shibyan: Jurnal Pendidikan dan Konseling | Vol. 4, No. 02 (2021) Licensed under CC-BY-SA (c) (i) () 
\& Schnur: 2020 ; Suci, dkk: 2018). Model pembelajaran Picture and Picture mengandalkan gambar sebagai media dalam proses pembelajaran bagi anak. Penggunaan gambar dalam pembelajaran mengenalkan warna dapat menstimulus anak untuk mengeksplorasi warna berdasarkan indra penglihatan (Dowd: 2018; Murni \& Rachmayani: 2019). Gambar-gambar yang diberikan merupakan gambar-gambar yang dikenali dan berada di sekitar anak. Adanya berbagai permasalahan di atas, sehingga perlu pengkajian lebih dalam terkait variasi pembelajaran pengenalan warna untuk anak usia dini. Karena itu penulis tertarik untuk mengkaji lebih lanjut tentang Mengenalkan Warna Melalui Model Pembelajaran Picture and Picture pada Anak Usia Dini.

\section{METODE PENELITIAN}

Penelitian ini berupa penelitian kuantitatif dengan metode quasi eksperiment dengan menggunakan uji one group time series dalam pemberian treatment kepada anak. Pemberian treatment dalam uji time series pada penelitian ini menggunakan empat kali uji coba. Subjek yang digunakan dalam penelitian ini sebanyak 150 orang anak yang ditentukan berdasarkan usia anak. Perilaku yang muncul dinilai berdasarkan indikator kemampuan mengenal warna bagi anak yang sesuai dengan aspek kognitif anak usia empat hingga lima tahun, yakni aspek kemampuan menunjuk, menyebut dan mengelompokkan warna.

Indikator tersebut dibagi menjadi per-treatment, yakni pada kemampuan mengenal 1-3 variasi warna (warna primer), dan kemampuan mengenal 1-5 variasi warna (warna sekunder). Segala prilaku yang muncul merupakan data penelitian yang dikumpulkan berdasarkan observasi yang dilakukan oleh peneliti dan guru. Data yang diperoleh dianalisis menggunakan uji Kruskal Wallis dan uji regresi untuk melihat seberapa besar peran model pembelajaran yang digunakan pada variabel kemampuan anak dalam mengenal warna dengan menggunakan SPSS.

\section{HASIL DAN PEMBAHASAN}

Kemampuan anak dalam mengenal warna dinilai dari kemampuan menunjuk, menyebut dan mengelompokkan. Pada treatment satu hingga ke empat, guru memberikan gambar-gambar yang memiliki tiga warna primer yakni warna merah, kuning dan biru. Anak diminta untuk memilih beberapa potongan kertas berwarna kemudian 
menunjukkan, menyebutkan dan mengelompokkan warna sesuai dengan gambar yang memiliki objek yang berwarna. Seperti halnya gambar bunga mawar, bintang dan tas biru, anak diminta menyebutkan warna tersebut dari gambar yang tersedia dan mengelompokkan serta mengurutkan kertas warna berdasarkan warna pada gambar-gambar tersebut. Berdasarkan treatment yang diberlakukan pada pertemuan pertama hingga ke empat berikut capaian perkembangan anak dalam kemampuan mengenal warna, yakni:

Tabel 1. Kemampuan Mengenal Warna Treatment 1-4

\begin{tabular}{|c|c|c|c|}
\hline & Null Hypothesis & Sig. & Decision \\
\hline 1 & $\begin{array}{l}\text { The distribution of Tr1 is normal vitEne-Sample } \\
\text { mean } 2.39 \text { and standard deviation Kolmogorov- } \\
0.43 \text {. Smirnov Test }\end{array}$ & .000 & $\begin{array}{l}\text { Reject the } \\
\text { null } \\
\text { hypothesis. }\end{array}$ \\
\hline 2 & $\begin{array}{l}\text { The distribution of } T h \text { is nomal withne-Sample } \\
\text { mean } 2.89 \text { and standard deviation Kolmogorov- } \\
0.34 \text {. Smirnov Test }\end{array}$ & .000 & $\begin{array}{l}\text { Reject the } \\
\text { nuil } \\
\text { hypothesis. }\end{array}$ \\
\hline 3 & $\begin{array}{l}\text { The distribution of } T B \text { is normal withne-Sample } \\
\text { mean } 3.12 \text { and standard deviation Kolmogorov- } \\
0.45 \text {. Smirnow Test }\end{array}$ & .000 & $\begin{array}{l}\text { Reject the } \\
\text { nuil } \\
\text { hypothesis. }\end{array}$ \\
\hline 4 & $\begin{array}{l}\text { The distribution of Tr4 is normal witine-Sample } \\
\text { mean } 3.38 \text { and standard deviation Kolmogorov- } \\
0.48 \text {. Sminov Test }\end{array}$ & .000 & $\begin{array}{l}\text { Reject the } \\
\text { nuli } \\
\text { hypothesis. }\end{array}$ \\
\hline
\end{tabular}

Asymptotic significances are displayed. The significance level is 05 .

Berdasarkan hasil uji Kruskal Wallis melalui SPSS diperoleh hasil data yang tertera pada tabel 1 bahwa setiap treatment yang diberikan memberikan pengaruh yang signifikan dalam capaian kemampuan anak dalam memahami warna. Hal ini dapat dilihat dari nilai Sig. pada tabel 1 yang bernilai 0.00 yang lebih kecil dari nilai ketetapan sebesar 0,05 . Selain itu, nilai mean yang ditampilkan menunjukkan adanya peningkatan nilai skor yang diperoleh anak dari setiap treatmement yang diberikan. Penggunaan model picture and picture memberikan kesempatan bagi anak untuk mengeksplorasi kemampuan anak dalam memahami warna.

Tabel 2. Regresi Kemampuan Memahami Warna Anak

Model Summary

\begin{tabular}{rrrrr}
\hline Model & $R$ & $R$ Squence & $\begin{array}{c}\text { Adjusted } R \\
\text { Squence }\end{array}$ & $\begin{array}{c}\text { Std. Error of the } \\
\text { Estimate }\end{array}$ \\
\hline 1 & $.803^{\mathrm{a}}$ & .645 & .638 & .26048 \\
\hline
\end{tabular}

a. Predictors: (Constant), Tr4, Tr2, Tr3

Tabel 2 menunjukkan bahwa nilai $\mathrm{R}^{2}$ memiliki nilai sebesar 0,645. Hal ini memiliki makna bahwa capaian kemampuan memahami warna pada anak mampu distimulus melalui pembelajaran picture and picture

86 mitra Ash-Shibyan: Jurnal Pendidikan dan Konseling | Vol. 4, No. 02 (2021) Licensed under CC-BY-SA (c) (1) () 
sebesar $64,5 \%$. Sedangkan sisanya yakni 35,5\% dijelaskan oleh variabel lainnya yang tidak terdapat dalam variabel yang digunakan dalam penelitian ini.

Tabel 3. Regresi Kemampuan Memahami Warna Anak

ANOVAa

\begin{tabular}{llrrrrr}
\hline \multicolumn{1}{c}{ Model } & $\begin{array}{c}\text { Sum of } \\
\text { Squares }\end{array}$ & \multicolumn{1}{c}{ Df } & $\begin{array}{l}\text { Mean } \\
\text { Square }\end{array}$ & \multicolumn{1}{c}{$\boldsymbol{F}$} & Sig. \\
\hline \multirow{2}{*}{1} & Regression & 18.029 & 3 & 6.010 & 88.573 & $.000^{\mathrm{b}}$ \\
Residual & 9.906 & 146 & .068 & & \\
& Total & 26.935 & 149 & & & \\
\hline
\end{tabular}

a. Dependent Variable: kemampuan Mengenal Warna Anak Tr 1-4

b. Predictors: (Constant), $\operatorname{Tr} 4, \operatorname{Tr} 2, \operatorname{Tr} 3$

Uji simultan pada tabel 3 menunjukkan output dapat menguatkan hasil uji Kruskal Wallis yang telah dipaparkan pada tabel 1. Penelitian ini menghasilkan data yang menunjukkan bahwa treatment pembelajaran dengan menggunakan picture and picture memberikan pengaruh yang signifikan terhadap kemampuan anak dalam mengenal warna. Pada tabel 1 dan tabel 3 dapat dilihat bahwa nilai signifikasi pada tabel tersebut memiliki nilai 0.00 yang lebih kecil dari 0,05 yang berarti bahwa kemampuan anak dalam mengenal warna dapat distimulus secara signifikan dengan menggunakan picture and picture.

Banyak manfaat yang diperoleh ketika anak mengenal warna sejak dini, antara lain dapat mengembangkan kecerdasan, bukan hanya mengasah kemampuan mengingat, tapi juga imajinatif dan artistik, pemahaman ruang, keterampilan kognitif, serta pola berpikir kreatif (Brunk, L., \& Møller, P: 2019 ; Rapisa, 2019). Pengenalan warna juga tidak terlepas dari proses pengindraan yaitu penglihatan mata. Anak melihat obyek benda (bentuk dan warna) masuk ke dalam mata melalui lensa mata yang kemudian diterima oleh bintik kuning diteruskan oleh syaraf mata (penglihatan) ke otak pusat. Melalui proses penglihatan (warna) tersebut dapat merangsang perkembangan syaraf otak khususnya syaraf otak anak usia dini yang baru belajar mengenal obyek benda (warna) (Dowd: 2018 ; Munafiah, dkk: 2018).

Mengenal warna dapat membantu anak untuk menstimulasi kepekaan penglihatan anak (Lee, et al: 2016). Guru memiliki peran dalam memberikan stimulasi secara terus menerus kepada anak agar anak dapat mengingat apa yang dilihat dan dipelajari. Salah satunya dengan melatih konsentrasi penglihatan anak dengan benda atau warna-warna yang

mitra Ash-Shibyan: Jurnal Pendidikan dan Konseling | Vol. 4, No. 02 (2021) 87 Licensed under CC-BY-SA (c) (i) () 
mencolok dengan menggunakan warna-warna primer dan sekunder (Grandgeorge \& Masataka: 2016). Pengenalan warna bermanfat untuk meningkatkan daya pikir serta kreativitas anak, melalui aktivitas mengenal warna juga mampu mendorong anak membuat inovasi besar, kepekaan anak akan meningkat terhadap suatu objek yang dilihatnya, sehingga anak juga akan mampu membedakan dan menganalisa.

Pengenalan warna merupakan bagian dari perkembangan kognitif yang harus dikembangkan sejak anak usia dini. Membutuhkan stimulasi yang tepat sehingga dapat tercapai perkembangannya dengan baik (Storkel, et al: 2017). Anak usia dini diharapkan menguasai berbagai konsep warna primer dan sekunder dalam lima variatif warna (Lanna \& Oro: 2019). Berdasarkan penelitian yang dilakukan anak mampu mengenal variatif warna tersebut dengan distimulus oleh pembelajaran picture and picture.

Pengenalan warna melalui picture and picture dibuat dalam aktivitas yang menyenangkan, tidak hanya untuk anak-anak tapi juga orang dewasa. Selain menyenangkan, pembelajaran yang diberikan diharapkan dapat bermakna bagi capaian perkembangan anak. Penggunaan pembelajaran dengan menggunakan picture and picture menjadi salah satu pilihan dalam pembelajaran mengenalkan warna bagi anak usia dini. Pembelajaran dengan picture and picture merupakan suatu pembelajaran yang menggunakan peran gambar yang dipasangkan atau diurutkan menjadi urutan logis berdasarkan tujuan pembelajaran. Model pembelajaran picture and picture mengandalkan gambar sebagai media dalam proses pembelajaran bagi anak. Penggunaan gambar dalam pembelajaran mengenal warna bagi anak dapat menstimulus anak untuk mengeksplorasi warna berdasarkan indra penglihatan anak. Gambargambar yang diberikan merupakan gambar-gambar yang anak kenali dan berada disekitar anak.

\section{SIMPULAN}

Penggunaan model pembelajaran picture and picture menjadi salah satu pilihan untuk mengenalkan warna kepada anak usia dini. Kemampuan anak dalam mengenal warna dinilai dari kemampuan menunjuk, menyebut dan mengelompokkan. Penelitian ini menunjukkan bahwa penggunaan model picture and picture berpengaruh secara signifikan terhadap kemampuan mengenal warna pada anak. Mengenal

88 mitra Ash-Shibyan: Jurnal Pendidikan dan Konseling | Vol. 4, No. 02 (2021) Licensed under CC-BY-SA (c) (i) () 
warna sejak anak usia dini banyak sekali manfaat yang dapat peroleh, antara lain anak dapat mengembangkan kecerdasan, bukan hanya mengasah kemampuan mengingat, tapi juga imajinatif dan artistik, pemahaman ruang, keterampilan kognitif, serta pola berpikir kreatif. Harapannya akan ada penelitian lebih lanjut untuk mengembangkan model ini agar menjadi lebih baik dalam mengoptimalkan perkembangan anak usia dini.

\section{DAFTAR PUSTAKA}

Brunk, L., \& Møller, P. (2019). Do children prefer colored plates?. Food Quality and Preference, 73, 65-74.

Dowd, N. E. (2018). Introduction, in Reimagining Equality: A New Deal for Children of Color. Reimagining Equality: A New Deal for Children of Color, 18-10.

Erviana, R., Ahmad, K. I., \& Sari, N. P. (2019). Developing Cognitive Ability to Matching Numbers and Symbol Using a Combination of Models, Methods, and Media Learning. Journal of K6 Education and Management, 2(4), 271-282.

Febriana, Putri. (2012). Mengenal Warna, Bentuk, Ukuran, dan Tempat. Jakarta: PT. TransMedia

Grandgeorge, M., \& Masataka, N. (2016). Atypical color preference in children with autism spectrum disorder. Frontiers in psychology, 7, 1976.

Harvey, D. Y., \& Schnur, T. T. (2016). Different loci of semantic interference in picture naming vs. word-picture matching tasks. Frontiers in psychology, 7, 710.

Hodayati, Sri., Robingatin., \& Saugi, Wildan, (2020). Meningkatkan Kemampuan Mengenal Warna Melalui Kegiatan Mencampur Warna di TK Kehidupan Elfhaluy Tenggarong. Yaa Bunayya: Jurnal Pendidikan Anak Usia Dini, 4(1), 23-37

Lanna, L. C., \& Oro, M. G. (2019). Touch gesture performed by children under 3 years old when drawing and coloring on a tablet. International Journal of Human-Computer Studies, 124, 1-12.

Lee, C. H., Jin, S. H., \& Lee, W. H. (2016). A Study of Psychotherapy Plan through Game Graphics Focused on Color Preference of Children. International Journal of u-and e-Service, Science and Technology, 9(7), 287-298.

Lopatovska, I., Hatoum, S., Waterstraut, S., Novak, L., \& Sheer, S. (2016). Not just a pretty picture: visual literacy education through art for young children. Journal of Documentation.

Macdonald, R., Brandt, S., Theakston, A., Lieven, E., \& Serratrice, L. (2020). The Role of Animacy in Children's Interpretation of Relative Clauses in English: Evidence from Sentence-Picture Matching and Eye Movements. Cognitive science, 44(8), e12874.

Marchak, K. A., Bayly, B., Umscheid, V., \& Gelman, S. A. (2020). Iconic Realism or Representational Disregard? How Young Children and Adults Reason about Pictures and Objects. Journal of Cognition and Development, 1-23. 
Murni, S., \& Rachmayani, R. (2019). The Cognitive Aspect Development of Matching Numbers Symbols in Children. Journal of K6 Education and Management, 2(4), 283-291.

Pradina, Y. A., \& Hastuti, W. D. (2017). The Effect of Picture and Picture Learning Model towards Science Outcomes for Students with Hearing Impairment in the Class VII. Journal of ICSAR, 1(2), 145-149.

Raj, D., \& Ganapathy, D. (2019). Childrens preference toward color of compomer fillings. Drug Invention Today, 12(9).

Rapisa, Dewi R. (2019). Program Latihan Koordinasi Sensorimotorik Bagi Anak Usia Dini dan Anak Berkebutuhan Khusus. Yogyakarta: Penerbit Deepublish

Suci, S. H. A., Rosyidah, E., Asitah, N., Aini, N., Murni, A. W., Anam, F., ... \& Kuraesin, A. D. (2018, November). Learning from Picture and Picture Action Research: Enhancement of Counting Ability on Division of Numbers for Primary School Students. In Journal of Physics: Conference Series (Vol. 1114, No. 1, p. 012044). IOP Publishing.

Storkel, H. L., Komesidou, R., Fleming, K. K., \& Romine, R. S. (2017). Interactive book reading to accelerate word learning by kindergarten children with specific language impairment: Identifying adequate progress and successful learning patterns. Language, speech, and hearing services in schools, 48(2), 108-124.

90 mitra Ash-Shibyan: Jurnal Pendidikan dan Konseling | Vol. 4, No. 02 (2021) Licensed under CC-BY-SA (c) (1) () 